Review

\title{
Churg-Strauss Syndrome or Eosinophilic Granulomatosis with Polyangiitis
}

\author{
Adriana Izquierdo-Domínguez ${ }^{1,2, *}$, Arturo Cordero Castillo ${ }^{3}$, Isam Alobid ${ }^{3,4}$ and \\ Joaquim Mullol ${ }^{3,4}$
}

1 Department of Pneumology and Allergy, Immunoallergia Respiratoria Clinica I Experimental, Hospital Clinic, 08950 Barcelona, Spain

2 Clínica Diagonal, 08950 Barcelona, Spain

3 Rhinology Unit and Smell Clinic, Department of Otorhinolaryngology, Hospital Clinic, University of Barcelona, 08950 Barcelona, Spain; E-Mails: arturocordero@hotmail.com (A.C.C.); isamalobid@gmail.com (I.A.); jmullol@clinic.ub.es (J.M.)

4 Laboratory of Clinical and Experimental Respiratory Immunoallergy, IDIBAPS, 08950 Barcelona, Spain

* Author to whom correspondence should be addressed; E-Mail: adrianaeizquierdo@hotmail.com; Tel.: +34-93-227-9872; Fax: +34-93-227-5050.

Academic Editor: César Picado

Received: 31 October 2015 / Accepted: 14 December 2015 / Published: 17 December 2015

\begin{abstract}
Eosinophilic granulomatosis with polyangiitis (Churg-Strauss, EGPA) is a systemic small-to-medium-sized vasculitis associated with asthma and eosinophilia. Histologically EGPA presents tissue eosinophilia, necrotizing vasculitis, and granulomatous inflammation with eosinophil tissue infiltration. EGPA commonly involves the upper airway and lung parenchyma, peripheral neuropathy, cardiac disorders, and skin lesions. The anti-neutrophil cytoplasmic antibodies (ANCA) are positive in $40 \%$ of cases, especially in those patients with clinical signs of vasculitis. The pathogenesis of EGPA is multifactorial. The disease can be triggered by exposure to a variety of allergens and drugs, but a genetic background has also been described, particularly an association with HLA-DRB4. Th2 response is of special importance in the upregulation of different interleukins such as IL-4, IL-13, and IL-5. Th1 and Th17 responses are also of significance. Activated eosinophils have a prolonged survival and probably cause tissue damage by releasing eosinophil granule proteins, while their tissue recruitment can be regulated by chemokines such as eotaxin-3 and CCL17. Humoral immunity is also
\end{abstract}


abnormally regulated, as demonstrated by excessive responses of $\mathrm{IgG}_{4}$ and IgE. EGPA has a good respond to glucocorticoids, although the combination of glucocorticoids and immunosuppressants (e.g., cyclophosphamide, azathioprine) is needed in most of cases. Newer treatment options include anti-IL-5 antibodies (mepolizumab), whose efficacy has been described in clinical trials, and anti-CD-20, a B cell-depleting agent (rituximab), reported in several case series.

Keywords: eosinophilic granulomatosis with polyangiitis; vasculitis; asthma; eosinophilia; glucocorticoids

\section{Introduction}

The Churg-Strauss syndrome (CSS) was described in 1951 by scientists Jacob Churg and Lotte Strauss, who correlate these pathological and clinical findings, as a syndrome characterized by asthma, fever, eosinophilia, as well as symptoms of heart failure, kidney damage, and peripheral neuropathy resulting from a vascular compromise in different organs and systems [1]. The histology of the 13 cases examined by Churg and Strauss were quite similar [1]. They found tissue eosinophilia, granulomatous, and necrotizing vascular lesions and extravascular granulomas in most organs. These syndromic characteristics could be differentiated from the classic polyarteritis nodosa and granulomatosis with polyangiitis (Wegener, GPA). In most of cases upper and lower airway manifestations appear associated in the form of asthma, allergic rhinitis, and chronic rhinosinusitis with nasal polyps. Referred to as Churg-Strauss syndrome (CSS) for many years, it now recognized, following the 2012-revised nomenclature, as eosinophilic granulomatosis with polyangiitis (EGPA) [2].

The histological lesions observed in the affected organs of CSS patients were extremely severe. Most of the biopsies were obtained from autopsy cases, facilitating the presentation of EGPA histological findings. Glucocorticoids have dramatically changed the prognosis of the EGPA. Patients usually receive glucocorticoids before diagnosis, which may change the severity and histopathological lesions observed today $[1,3]$.

The knowledge and understanding of EGPA has evolved in recent years. Since anti-neutrophil cytoplasmic antibodies (ANCA) have been found in a proportion of patients, EGPA has subsequently been included in the spectrum of ANCA-associated vasculitis (AAV), along with GPA and microscopic polyangiitis (MPA) [4]. Several studies have elucidated the role of immune mechanisms, identifying genetic associations with HLA-DRB4 while recognizing new diagnostic and follow-up biomarkers (e.g., eotaxin-3) [5-11]. Finally, the treatment approach has improved through the use of immunosuppressive drugs and biological treatments. Rituximab, a B cell-depleting agent, has been used in individual cases, whereas mepolizumab, an anti-IL-5 antibody, has shown efficacy in a pilot study [12].

This review focuses on the areas of current evidence considering CSS classification, epidemiology, symptoms, diagnosis, prognosis, and treatment, especially from a respiratory approach, and attempts to identify the advances in the development and progression of the disease. 


\section{Definition and Classification}

There are no commonly accepted diagnostic criteria for EGPA. In 1984, Lanham et al. proposed that patients with EGPA should have asthma, eosinophilia, and vasculitis involving two or more organs [13]. In 1990 the American College of Rheumatology (ACR) classification criteria were established to distinguish the different forms of vasculitis. The ACR classification criteria included asthma, blood eosinophilia ( $>10 \%)$, neuropathy, non-fixed lung infiltrates, paranasal sinus abnormalities, and extravascular eosinophils on biopsy. When four or more of these criteria are met, classification of vasculitis as EGPA can be made with high sensitivity (85\%) and specificity (99.7\%) [14]. As the ACR criteria were established for classification purposes (and not diagnosis) it can however only be used to define the type of vasculitis. In 1993, at the Chapel Hill consensus, definitions including exclusive clinical-pathological criteria for primary vasculitis were developed [4]. The chronology is summarized in Figure 1.

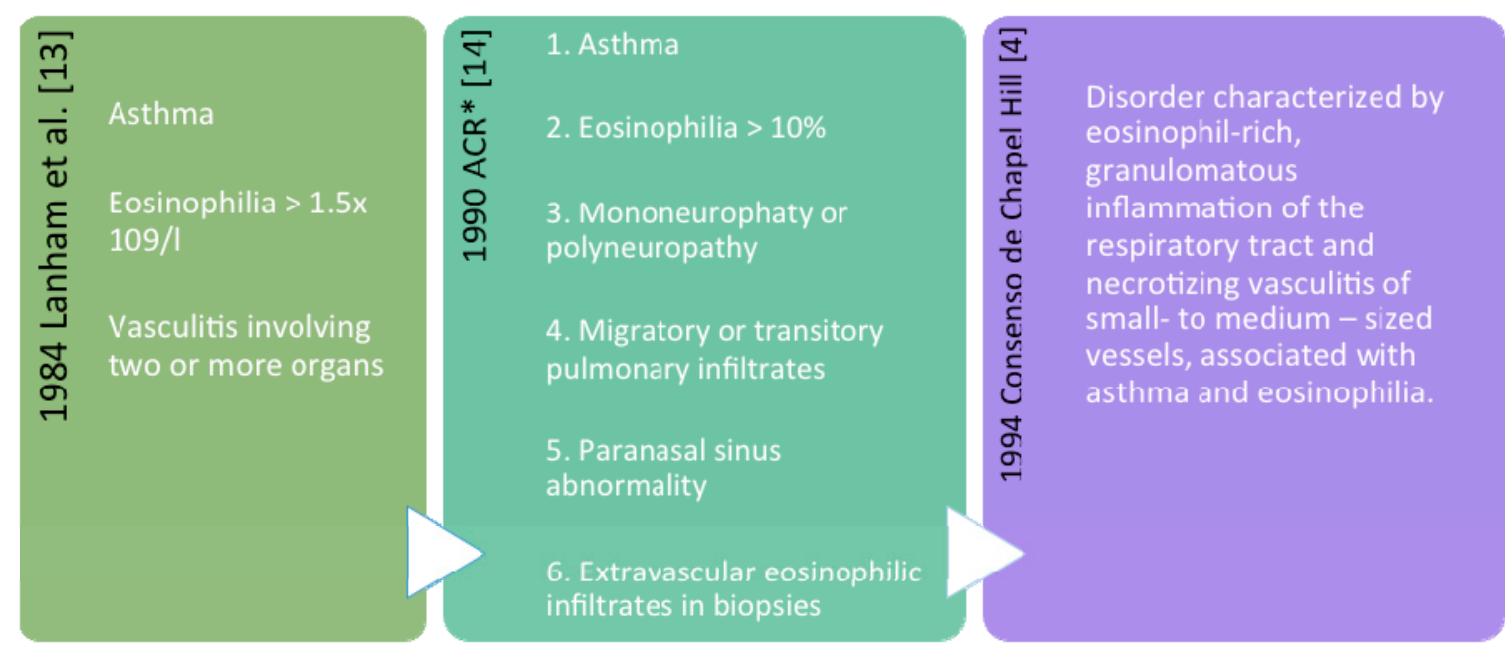

Figure 1. Definitions and classification criteria commonly used for Eosinophilic Granulomatosis with PolyAngiitis (EGPA): Lanham criteria, ACR (American College of Rheumatology) classification criteria, and definition of Chapel Hill. * When four or more criteria are met, vasculitis can be classified as EGPA with high sensitivity $(85 \%)$ and specificity $(99.7 \%)$.

\section{Nomenclature}

Recently, a group of experts has decided to rename the Churg-Strauss Syndrome as "Eosinophilic Granulomatosis with PolyAngiitis (EGPA)" [2]. Although both terms can be used, EGPA is more descriptive than the eponymous CSS for the purpose of classifying the disease.

\section{Epidemiology}

EGPA is a rare disease, with an estimated annual incidence of $0.5-4.2$ cases/1,000,000 inhabitants, which has been found to be stable in recent years, with a prevalence of 11-14 cases/1,000,000 inhabitants [15-18]. It usually presents between 40 and 60 years of age, with a mean age onset of 
49 years [19]. Although pediatric cases have also been described, no clear gender predominance, family clustering, or ethnic predisposition has been clearly found [20,21].

\section{Genetic and Environmental Factors}

Immunogenetic factors may confer susceptibility to EGPA. The HLA-DRB1 $* 04$ and $* 07$ alleles and the HLADRB4 gene are associated with an increased risk of developing EGPA $[7,8]$. The finding of an association with HLA, as in other autoimmune diseases, supports the hypothesis of an antigen-targeted disease. Interestingly, the group of patients with ANCA-negative EGPA was associated with the haplotype IL10.2 of the IL-10 promoter polymorphism, functionally resulting in an increase expression of IL-10 [22]. Other nucleotide polymorphisms have shown little or no effect on EGPA susceptibility [23-25].

Harmanci et al. described a family history of EGPA, with mother and daughter being affected, yet the genetic factors influencing disease susceptibility have not been identified until now. This constitutes the second report of the EGPA family [26].

It has long been suspected that EGPA is triggered by exogenous factors, including environmental agents, infections, vaccines, and medications. Although studied in a small number of patients, exposure to silica particles has also been considered a risk factor for EGPA, as it was for other VAA [27,28].

The role of infections and vaccines in EGPA still remains unclear and no isolated infectious agent or vaccination type has demonstrated a causal role. A variety of studies have described the development of EGPA after treatment with different drugs such as macrolide antibiotics and particularly leukotriene receptor antagonists (LRAs) [29,30]. Different hypotheses have been proposed to explain how LRAs induce EGPA in asthmatic patients: (a) they may unmask silent forms of EGPA since their use reduces the need for corticosteroids; (b) they have a direct pathogenic role or may cause idiosyncratic allergic reactions; and (c) the association between LRAs and EGPA, although temporarily related, may simply be a coincidence, and the progression from asthma to EGPA may reflect the natural course of the disease which initially displays an allergic manifestation and subsequent eosinophilic and vasculitic complications. A reduction in the dose of corticosteroids certainly provides a possible causal relationship between LRAs and EGPA. This fact is also supports by other steroid-sparing drugs used for asthma like theophylline, chromones, and omalizumab (anti-IgE) that apparently precipitate EGPA. An interesting study of crossed cases by Hauser et al. may confirm this hypothesis [31-34]. However, a recent analysis by Bibby et al. examined the association between LRA treatment and the development of EGPA in detected cases from the Reporting System Adverse Reactions FDA (Food and Drug Administration) database, and concluded that treatment with LRAs was suspected of causing EGPA in 114 cases. In two thirds of these, however, a preexisting association or a potential prodromal phase was not possible, possibly due to the reduction of oral or systemic glucocorticoids [35].

Currently have been described cases in remission with omalizumab, in pediatric patient after previous treatment with corticosteroids, immunoglobulins, cyclophosphamide and mycophenolate [36]. Another case of EGPA was described in a patient treated with omalizumab who remained with severe uncontrolled asthma despite high doses of glucocorticoids. Treatment was initiated in 2008, and to date the patient has had no hospitalizations for respiratory failure, IgE levels being significantly reduced [37]. 


\section{Clinical Features}

EGPA is considered a systemic disease and typically evolves in prodromal phases. The allergic phase is characterized by asthma and chronic rhinosinusitis, the eosinophilic phase by peripheral eosinophilia and involvement of different organs, and the vasculitis phase by clinical manifestations due to small vessel vasculitis [38]. These phases partially overlap and do not appear in a defined order, although asthma and chronic rhinosinusitis rarely arise after vasculitic manifestations [39].

The typical case in which EGPA should be suspected is that of a patient with adult-onset asthma and a history of chronic rhinosinusitis who develops eosinophilia and pulmonary infiltrates. Although uncommon, eosinophilia may occur in asthmatic patients but is usually mild $(<10 \%)$ while pulmonary infiltrates due to mucus bronchial obstruction and superimposed infection may complicate asthma [39].

\section{Specific Organs}

There are "limited" forms of EGPA affecting individual organs [40]. In these cases, diagnosis is made by histology.

\subsection{Upper Airways}

Allergic rhinitis, chornic rhinosinusitis, and nasal polyps are characteristic of the prodromal phase [41]. Nasal polyps affect about $50 \%$ of EGPA patients and systematically recur after surgery in patients who have not received medical therapy [42]. Chronic rhinosinusitis affects up to $75 \%$ of patients as an allergic manifestation or granulomatous inflammation $[43,44]$. Other ENT manifestations include chronic ear drainage, serous otitis media, sensorineural hearing loss, and facial nerve palsy, especially in advanced stages of the disease [41].

\subsection{Lower Airways}

Asthma is present in $95 \%-100 \%$ of the patients and for many years may precede the systemic manifestations of the disease. It usually arises in adulthood with different levels of severity [38]. Unlike extrinsic asthma, seasonal exacerbations are not observed in EGPA [45].

The eosinophilic phase is characterized by lung, cardiac and gastrointestinal involvement. The pulmonary parenchyma is affected in up to two thirds of the patients [46]. Migratory peripheral infiltrates are usually observed by chest X-ray. High-resolution CT scan shows ground-glass opacities, consolidation areas, thickening of the bronchial wall and small centrilobular nodules [47]. Alveolar hemorrhage affects $3 \%-8 \%$ of patients $[48,49]$. Pleural effusion secondary to eosinophilic pleuritis or eosinophilic cardiomyopathy with congestive heart failure may also be found.

\subsection{Other Organs and Systems}

Symptomatic cardiac involvement is associated with a poor prognostic factor $[19,50]$. In a retrospective analysis of 49 patients, 22 (45\%) had clinical evidence of heart disease, 13 of them having positive MRI or histologic evidence of endomyocarditis, which was associated with impaired cardiac function and thrombus formation [51]. Peripheral eosinophilia is higher in patients with cardiac 
involvement who have initial lesions with eosinophilic infiltration, with these patients developing restrictive cardiomyopathy secondary to fibrotic changes.

Although endomyocardial infiltration is the dominant condition, pericarditis, vasculitis, valvular heart defects, and abnormalities may also occur [52]. In addition, patients with EGPA have an increased risk of venous thromboembolic events, such as deep venous thrombosis and/or pulmonary embolism [53].

Gastrointestinal involvement is also due to eosinophilic infiltration of the gastrointestinal mucosa and frequently affects the small bowel, which may present abdominal pain and sometimes gastrointestinal bleeding. In rare cases it can present as cholecystitis [54-56].

The vasculitic phase starts with general symptoms (e.g., fever, fatigue, weight loss) and often with an apparent and paradoxical improvement of asthma. Peripheral neuropathy is a cardinal feature of this phase, which affects up to $70 \%$ of patients $[49,55,57]$. In electrophysiological studies, EGPA is characterized by axonal damage, often affecting the peroneal, tibial, ulnar, and median nerves. The typical manifestation is multiplex mononeuritis with asymmetric drop of wrist or foot, but this can also evolve to symmetric or asymmetric polyneuropathy. Neuropathic pain and sensory deficits are also frequent [58].

Renal manifestations occur in $25 \%$ of patients and range from isolated urinary abnormalities (e.g., microscopic hematuria, proteinuria) to rapidly progressive glomerulonephritis. Histology shows pauci-immune focal and segmental necrotizing glomerulonephritis, with or without crescents, which is often less severe than in other AAV (3). Skin lesions, especially purpura, may also become a prominent feature of the vasculitic phase. Purpura occurs in $25 \%$ of cases and usually involves the lower limbs. Nodules, urticaria, livedo, and skin ulcers $[3,55]$ may also appear. Cardiac involvement frequently occurs at the vasculitic or generalized phase of the disease.

\section{ANCA Phenotypes}

There are a variety of clinical EGPA phenotypes. However, its clinical manifestations tend to be segregated into two main subsets, either dominated by vasculitic or eosinophilic features. The presence of ANCA can differentiate both subsets.

Two large studies have shown that ANCAs were positive in $38 \%$ of patients and those ANCA-positive patients more frequently had peripheral neuropathy, glomerulonephritis and purpura (which are due to vasculitis of small vessels), while pulmonary infiltrates and endomyocardial manifestations prevailed in the ANCA-negative phenotype [49,55]. In a more recent study, carried out in patients with EGPA from a FDA database of adverse events, ANCA-negative patients provided comparable results to those of the two previous studies compared with ANCA-positive anti-MPO [59]. These observations raised the question of whether ANCA can contribute to the development of vasculitis in EGPA. Further studies are needed to determine the prognostic role of ANCA and whether treatment should be tailored to the presence or absence of ANCA (Table 1). 
Table 1. Clinical Manifestations of Eosinophilic Granulomatosis with Polyangiitis (EGPA).

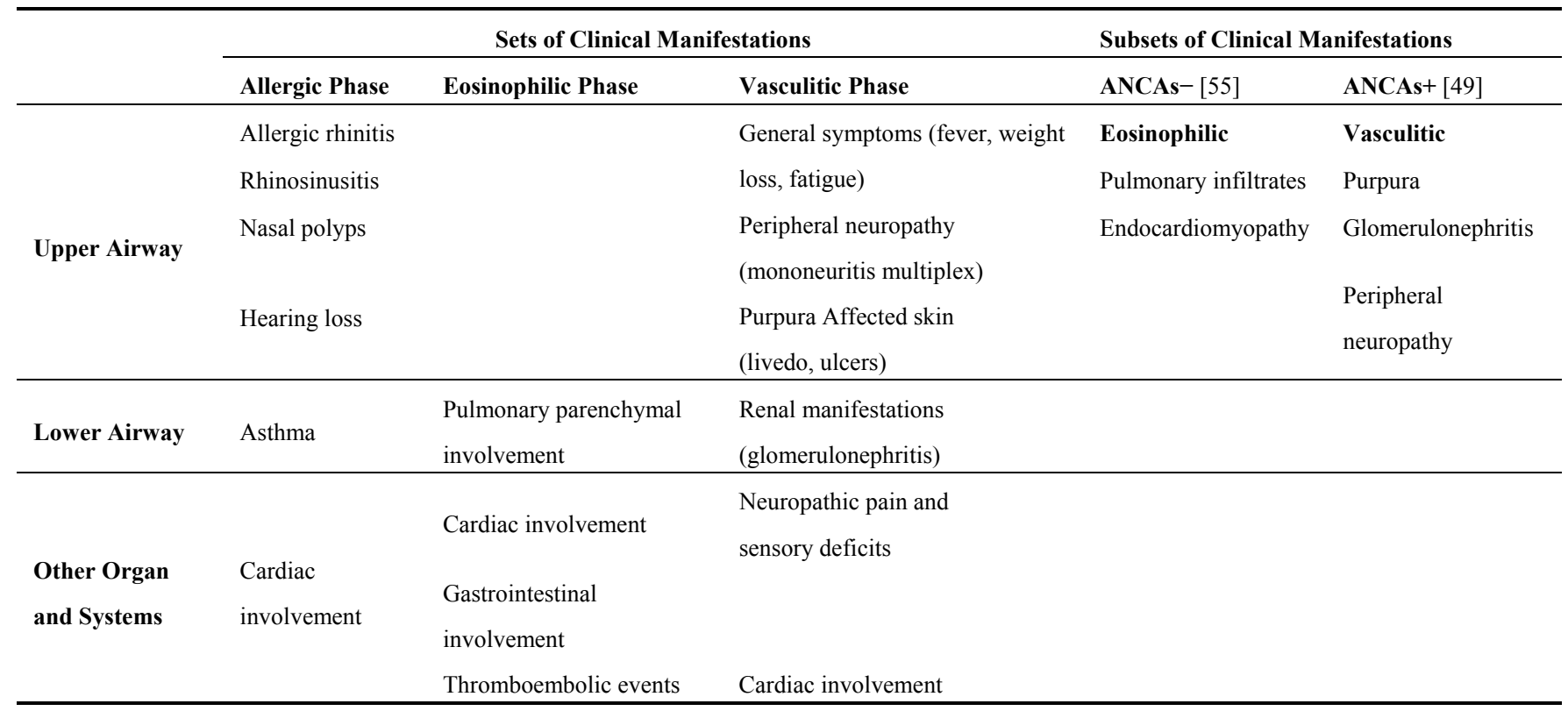

ANCAs: Anti-neutrophil cytoplasmic antibody.

A retrospective review of pediatric patients evaluated from 2003 to 2011, with a mean diagnosis age of 15 years, showed eosinophilia, involvement of upper and lower airways and, ANCA negativity in all patients [60].

\section{Diagnosis}

\subsection{Blood Cells and Biomarkers}

The EGPA active phase is characterized by marked peripheral blood eosinophilia $(>1500$ cells $/ \mu \mathrm{L}$ or $>10 \%$ ). Eosinophilia correlates with disease activity and relapses [61]. C-reactive protein (CRP) and erythrocyte sedimentation rate (ESR) are also higher in the active phase. Measurement of eosinophils and CRP, have shown to be the best markers associated with disease activity. Serum total IgE levels are elevated in most patients but they lack specificity for common allergens [45]. Recent data have shown that serum $\mathrm{IgG}_{4}$ levels were high in $75 \%$ of patients with active EGPA, better correlating with its activity than IgE [62]. ANCA may appear several years before the onset of vasculitis [63]. The perinuclear immunofluorescence (p-ANCA) pattern is found in 74\%-90\% of EGPA ANCA-positive cases, especially anti-MPO antibodies. The remaining cases are anti-cytoplasmic ANCA (c-ANCA) corresponding to anti-proteinase-3 or mixed patterns antibodies (p-ANCA + c-ANCA) [49].

Although there are no validated diagnostic tests for EGPA, new biomarkers are emerging. A recent study has shown a good diagnostic performance of eotaxin-3, a chemokine which induces eosinophil chemo-attraction. Serum levels were significantly higher in active EGPA than in a wide range of control groups (e.g., AAV, hyper-eosinophilic syndrome [HES]). It is important to highlight that all HES patients had active disease at the time of blood collection. In a cutoff point of $80 \mathrm{pg} / \mathrm{mL}$, the sensitivity and specificity of eotaxin-3 for diagnosing active EGPA was $87.5 \%$ and $98.6 \%$, respectively [11]. Although this biomarker needs diagnostic validation, it is likely to come into use in daily clinical practice. Recent studies have demonstrated elevated concentrations of proteins related to 
eosinophilia, particularly eotaxin-3, allowing to distinguish EGPA from other vasculitis or hyper-eosinophilia conditions [5]. Another marker of disease activity described in some studies is eosinophil cationic protein (ECP) [64].

Recently, Grayson PC et al. conducted a longitudinal study of biomarkers to evaluate disease activity while predicting relapse in patients with EGPA. They studied eosinophil count, serum total IgE, ESR, and CRP, concluding that these markers have some limitations and suggesting the need for new disease biomarkers [65].

\subsection{Histopathology}

The key histological characteristics of EGPA are eosinophilic tissue infiltration and/or necrotizing vasculitis and/or extravascular eosinophilic granulomas. Vasculitis is characterized by fibrinoid necrosis and eosinophil infiltration in the vascular wall. Granulomas may involve the arteries, but the most specific lesions of EGPA are extravascular granuloma, consisting of a core of necrotic eosinophilic material surrounded by lymphocytes with palisading epithelioid lymphocytes, and multinucleated giant cells $[1,14]$.

EGPA pathology varies according to the organ affected. The lung lesions can show all the aforementioned features, while heart disease usually shows endo- and pericardium eosinophilic infiltration but rarely coronary vasculitis. Similarly, histological gastrointestinal affection shows eosinophilic gastroenteritis and, in some cases, mesenteric vasculitis leading to ischemia [38,54]. In contrast, renal lesions show focal glomerulonephritis but rarely eosinophilic infiltration or granulomas. Peripheral neuropathy reveals epineural lymphocytic vasculitis with eosinophils, while purpura is due to leukocytoclastic vasculitis of dermal vessels, but usually lacks granulomatous or eosinophilic reactions.

\subsection{Imaging}

\subsubsection{Chest Radiography and CT Scan}

Patterns commonly find are lobar or segmental opacity, diffuse interstitial or miliar patterns, migratory infiltrates of the lower lobe or subpleural, hilar, or mediastinal lymphadenopathy, pleural effusion, and pulmonary hemorrhage, ground glass opacity and hyperinflation [66-68].

\subsubsection{Sinonasal CT Scan}

This is the imaging test of choice due to the optimal viewing and discrimination of pneumatic bone, solid bone, and soft tissue offered. As in patients with chronic rhinosinusitis without vasculitis, varying degrees of opacities can be visualized using Lund-Mackay score: $0=$ normal, $1=$ partial opacification, 2 = total opacification, for each of the paranasal sinuses (maxillary, ethmoid, sphenoid, and frontal). The ostiomeatal complex is scored as $0=$ not occluded, or $2=$ occluded. Unilateral is scored as 12 points, and bilateral, or total, as 24 points [69]. This scoring system is validated in several studies [70]. 


\subsubsection{Sinunasal Plain X-rays}

Despite the availability and low cost, its use for diagnosing rhinosinusitis is limited due to overlapping bony parts with soft tissue, compared with CT or MRI [71].

\subsection{Lung Function}

An obstructive or restrictive pattern predominates depending on whether the airway or parenchyma is involved. Airflow measurements are performed according to the treatment of asthma [45,72-74]. A reduction of diffusion capacity should lead to consideration of thromboembolic complications.

\subsection{Bronchoscopy}

In bronchoalveolar lavage, the presence of eosinophilic inflammation may be found, obviating the need for lung biopsy [75].

Histopathological diagnosis is made given the presence of eosinophilic infiltrates. It should be performed whenever possible through a biopsy of the more accessible affected tissue, such as nasal polyps, skin, lung, kidney, or nerves [76].

\section{Differential Diagnosis}

The differential diagnosis of EGPA particularly includes eosinophilic diseases and other vasculitis. A recent expert consensus on the management and evaluation of EGPA has recommended, as an initial test for differential diagnosis, serology for Toxocara and human immunodeficiency virus (HIV), as well as blood total IgE, IgG to Aspergillus spp, tryptase, and vitamin B12. To rule out eosinophils or blasts dysplasia, peripheral blood smears should also be performed [77].

\subsection{Hypereosinophilic Syndrome (HES)}

HES is characterized by marked and persistent eosinophilia ( $>1500$ cells $/ \mu \mathrm{L})$, organ involvement and the absence of "reactive" forms of eosinophilia (particularly parasitic and viral infections, medications, allergies, tumors, autoimmune or immunological diseases) [78]. In a recent classification by pathogenesis HES is subdivided into the following groups: (a) myeloid and lymphoid neoplasms with eosinophilia and abnormalities of PDGFRA (platelet derived growth factor receptor alpha), PDGFRB (beta) or FGFR1 (e.g., fusion of FIP1L1-PDGFRA gene); (b) chronic eosinophilic leukemia and other myeloid malignancies associated with eosinophilia without recognized genetic abnormalities; (c) a variant of lymphocytic HES (where a lymphocyte clone produces abnormally eosinophil hematopoietins, such as IL-5 or IL-3); and (d) idiopathic HES [78,79]. However, hematologic and molecular research techniques are required to distinguish these forms. Idiopathic HES may substantially overlap with EGPA since cardiac and lung manifestations may be similar in both pathologies, while patients with idiopathic HES rarely present either asthma or nasal polyps [80], or vasculitic complications (e.g., purpura, glomerulonephritis, neuropathy). In idiopathic HES tissue biopsies do not show vasculitis, and ANCA are typically negative [81]. It is particularly complicated to differentiate between EGPA ANCA-negative and HES. In a recent study comparing patients with 
EGPA ANCA-negative and HES FIP1L1-PDGFRA-negative, none of the analyzed serum biomarkers (sIL2R, IL-5, IL-6, IL-8, IL-10, CCL17, eotaxin-1) could differentiate between the two groups of patients [80]. As previously mentioned, eotaxin-3 could differentiate active EGPA from various forms of HES, as well as from other allergic or immune diseases associated with eosinophilia $[11,82]$.

\subsection{Allergic Bronchopulmonary Aspergillosis (ABPA)}

ABPA simulates an EGPA limited to the respiratory tract. Isolation of Aspergillus spp. in bronchoalveolar lavage (BAL) or sputum, and elevated serum levels of specific IgE to Aspergillus fumigatus account for the diagnosis of ABPA [83].

\subsection{Acute Eosinophilic Pneumonia}

This may present with pulmonary infiltrates and a BAL fluid rich in eosinophils, but usually begins as a severe febrile illness with respiratory failure, without peripheral eosinophilia and other systemic symptoms [84]. Chronic eosinophilic pneumonia is more insidious and patients may have asthma, peripheral eosinophilia and systemic symptoms such as weight loss, night sweats, and fever. The absence of ANCA and other organ manifestations can help differentiate this from EGPA [84]. Among eosinophilic disorders, those secondary to parasitic infections and to drug hypersensitivity should also be discarded.

\subsection{Other Vasculitis}

EGPA must be differentiated from other small vessel vasculitis. GPA may indeed overlap with EGPA, especially in cases with eosinophilia. The distinguishing characteristics include ANCA specificity (c-ANCA/ proteinase-3 ANCA being more frequent in GPA) and the presence, in GPA, of cavitated pulmonary nodules, nasal crusts and sinus bone erosions [38]. The MPA, usually associated with p-ANCA/ MPO-ANCA as in EGPA, rarely shows high eosinophilia and involvement of the upper airway while its renal complications are often more severe than in EGPA.

\subsection{IgG4-Related Disease}

Given the recent observation of raised $\mathrm{IgG}_{4}$ in EGPA, differential diagnosis should also include IgG4-related diseases, which may present with allergic manifestations, eosinophilia, pulmonary infiltrates, and rhinosinusitis. Tissue biopsies related with IgG4-disease reveals a storiform fibrosis pattern, obliterative phlebitis, in the absence of eosinophilic granulomas or vasculitis $[85,86]$. Systemic inflammation affecting thyroid, orbital region, salivary glands, pituitary, head and neck lymph nodes, as well as sinus cavities, are also well described as part of the repertoire of the IgG4-disease [87]. 


\section{Therapeutical Options}

\subsection{General Treatment}

There is no consensus regarding the use of a remission induction approach and maintenance of remission in EGPA. Patient's prognosis mainly determines the choice of initial therapy. Although it has not been validated internationally, some authors use the "Five Factors Score" (FFS) as prognostic index for EGPA [10]:

1. Cardiomyopathy

2. Gastrointestinal involvement

3. Central nervous system involvement

4. Proteinuria $(>1 \mathrm{~g} / 24 \mathrm{~h})$

5. Serum creatinine $(>150 \mathrm{mmol} / \mathrm{L})$

However Moosig et al. [19] chose the medication according to the activity and extent of the disease. In non-organ- or life -threatening disease, recommended the use of prednisolone as monotherapy. In cases of life- or organ-threatening manifestations, defines as alveolar hemorrhage, severe eosinophilic alveolitis, that is, leading to respiratory insufficiency and/or not responsive to glucocorticoids, involvement of kidneys, heart, peripheral nervous system, central nervous system, or gastrointestinal tract, cyclophosphamide therapy, and prednisolone were initiates.

\subsection{Glucocorticoids and Immunosupressants}

The presence of one or more risk factors (FFS $\geq 1$ ) indicates a worse prognosis and those patients are usually treated with glucocorticoids and immunosuppressants. Depending on the presence of risk factors, mortality at five years rises from $11.9 \%$ (no risk factors) to $25.9 \%$ (only one risk factor) and up to $46 \%$ (two or more risk factors). Glucocorticoids alone are recommended in patients with FFS $=0[88,89]$. This approach has been questioned by other authors that recommend a combination of immunosuppressants and corticosteroids as first-line therapy for patients with peripheral neuropathy and eosinophilic alveolitis or alveolar hemorrhage [19].

Cyclophosphamide has been successfully used for induction of remission in patients based on the FFS. In a randomized controlled trial comparing six or 12 pulses of cyclophosphamide administered with glucocorticoids, the two regimens were equally effective for inducing remission, but relapse prevailed in the six-pulse group [88].

Methotrexate has also been used for induction in a non-randomized trial. Remission was achieved in $73 \%$ of cases but remained at $50 \%$ in patients included in the analysis of long-term monitoring [90]. According to these data, a more recent study has shown that $>50 \%$ of patients previously treated with mepolizumab and in complete remission, relapsed when switching to methotrexate maintenance [64].

In a study of patients with FFS $=0$, remission was obtained with glucocorticoids alone in $>90 \%$ of cases, but relapses were found in $35 \%$ of cases during glucocorticoid dose reduction. Patients with treatment failure or relapse randomly received azathioprine or cyclophosphamide as adjuvant therapy, without significant differences on the results [89]. 
High doses of intravenous immunoglobulin were used in combination with plasma exchange, cyclophosphamide and glucocorticoids in a pilot trial. All patients achieved remission with a relapse rate of $11 \%$ during the 36 months of follow-up [91].

Given their ability to stop the response of eosinophil degranulation and Th2 in vitro, interferon-alpha has also been used for EGPA for the first time and with promising results in 1998 [92]. In a recent pilot study of seven patients with refractory disease, all achieved remission after three months of therapy with interferon-alfa [93]. These patients were included with seven others in a long-term follow-up study, evaluating interferon-alpha as maintenance treatment, and after a mean follow-up of 64 months, only three patients were receiving interferon while the others had discontinued due to lack of efficacy and/or adverse events [94].

\subsection{Biological Therapies (Monoclonal Antibodies)}

Recent clinical trials have shown that acting against IL-5, a main factor for eosinophil survival, significantly reduces asthma exacerbations in patients with sputum eosinophilia and allows the reduction of glucocorticoids in HES patients without the mutation FIP1L1- PDGFRA [95]. These results have made possible the use of anti-IL-5 therapy in EGPA, initially with efficacy in one case of EGPA refractory to other treatments [96].

Subsequently mepolizumab (anti-IL-5 antibodies) was administrated to seven glucocorticoid-dependent patients [97]. The average eosinophil count decreased by $75 \%$ with a substantial reduction of glucocorticoids (mean dose from 18.8 to $4.6 \mathrm{mg}$ ) in all patients. Even though the tolerance and safety of treatment were good, the clinical manifestations of EGPA reappeared when the treatment was stopped. More recently, mepolizumab has been used for induction of remission in a trial of patients with refractory or recurrent EGPA. Eight of the 10 recruited patients reached remission and were able to reduce the dose of glucocorticoids to below $7.5 \mathrm{mg} / \mathrm{d}$. No patient relapsed during treatment, but clinical manifestations reappeared after the withdrawal of mepolizumab [98].

B-cell depletion with rituximab, a chimeric anti-CD20 monoclonal antibody, effectively induces remission in AAV. Rituximab is administered to patients with EGPA refractory to standard therapy, although most studies are limited to case reports or small series [99,100]. In these cases, rituximab effectively induced remission and only two patients failed to complete treatment due to bronchospasm. Rituximab has also been used for kidney disease related to EGPA in a pilot trial of three patients who achieved remission [99]. Interestingly, rituximab not only induces clinical remission but also eosinophil count normalization and IL-5 reduction [101]. Since IL-5 is essentially produced by T-cells, this finding implies that B cell depletion strongly influences $\mathrm{T}$ cell function.

Biological therapies are still under investigation and in some countries are not approved for this indication.

\subsection{Chronic Rhinosinusitis with Nasal Polyps}

The main objective in the management of CRS with nasal polyps is to eradicate polyps and reduce sinonasal inflammation, eliminate symptoms, and prevent recurrences. Corticosteroids remain the first line and most effective treatment for CRS with nasal polyps. 
Other potentially effective treatments are saline nasal irrigation and antihistamines (only for allergic patients). Although some products have not shown real effectiveness (antibiotics, antifungals, nasal decongestants, proton-pump inhibitor), others may be effective but need more research to improve the level of evidence (anti-leukotrienes, aspirin desensitization, biological products such as anti-IgE and anti-IL-5, and immunosuppressants).

Endoscopic surgery is possible when initial medical treatment fails. After surgery, further treatment with nasal and oral corticosteroids is also recommended [102].

\section{Prognosis}

The prognosis of EGPA is good with respect to mortality. In a randomized trial of patients without poor prognostic factors, the one- and five-year survival rates were $100 \%$ and $97 \%$, respectively [89]. In the trial of patients with poor prognostic factors, 92\% remained alive after eight years of follow-up [88]. Finally, in a recent single-center retrospective analysis of 150 cases, survival rates at five and 10 years were $97 \%$ and 89\%, respectively [19]. Disease-associated organ damage (e.g., heart failure, chronic neuropathy) may however severely impair the quality of life of EGPA patients. Symptomatic cardiac involvement is associated with a poor prognostic factor [19,50]. Immunosuppressive therapy may also contribute to morbidity, particularly favoring the growth of malignant cells and infections. Patients from the above retrospective study were followed for a mean of 53.5 months, and the authors found seven malignant solid tumors and four types of non-melanoma skin cancer, along with 31 infections that required hospitalization (e.g., bacterial pneumonia, Pneumocystis carinii pneumonia and CMV). Interestingly, the dose of glucocorticoids was identified as a major risk factor for infection [19]. Other complications associated with glucocorticoids, such as osteoporosis, cataracts, and diabetes, were also common, emphasizing the importance of investigating new treatment strategies able to achieve complete and lasting remission, thereby reducing glucocorticoid intake.

\section{Conclusions}

CSS has been recently renamed as "Eosinophilic Granulomatosis with PolyAngiitis (EGPA)". It is a rare but severe systemic vasculitis that can affect almost every organ in the body. The upper and lower airways should be examined in all patients with CSS. The response of T and B cells along with the activation of eosinophils play an important role in the pathogenesis and ANCAs are the hallmark for the complications of vasculitic disease. When properly treated, EGPA has a good prognosis in comparison to other vasculitis and recent data suggest that biological agents such as mepolizumab (anti-IL-5) and potentially rituximab (anti-CD20) are two promising therapeutic options. Corticosteroids still remain the first-line treatment for the management of CRS with nasal polyps in EGPA, but endoscopic surgery is indicated when there is lack of control with medical treatment.

\section{Author Contributions}

I.A. and J.M. designed the research; A.I-D and A.C.C. wrote the manuscript. All authors discussed, edited and approved the final version. 


\section{Conflicts of Interest}

The authors declare no conflict of interest.

\section{References}

1. Churg, J.; Strauss, L. Allergic granulomatosis, allergic angiitis, and periarteritis nodosa. Am. J. Pathol. 1951, 27, 277-301.

2. Jennette, J.; Falk, R.; Bacon, P.; Basu, N.; Cid, M.; Ferrario, F.; Flores-Suarez, L.F.; Gross, W.L.; Guillevin, L.; Hagen, E.C.; et al. 2012 Revised international chapel hill consensus conference nomenclature of vasculitides. Arthritis Rheum. 2013, 65, 1-11.

3. Sinico, R.A.; di Toma, L.; Maggiore, U.; Tosoni, C.; Bottero, P.; Sabadini, E.; Giammarresi, G.; Tumiati, B.; Gregorini, G.; Pesci, A.; et al. Renal involvement in Churg-Strauss syndrome. Am. J. Kidney Dis. 2006, 47, 770-779.

4. Jennette, J.C.; Falk, R.J.; Andrassy, K.; Bacon, P.A.; Churg, J.; Gross, W.L.; Hagen, E.C.; Hoffman, G.S.; Hunder, G.G.; Kallenberg, C.G.; et al. Nomenclature of systemic vasculitides. Proposal of an international consensus conference. Arthritis Rheum. 1994, 37, 187-192.

5. Dallos, T.; Heiland, G.R.; Strehl, J.; Karonitsch, T.; Gross, W.L.; Moosig, F.; Holl-Ulrich, C.; Distler, J.H.; Manger, B.; Schett, G.; et al. CCL17/thymus and activation-related chemokine in Churg-Strauss syndrome. Arthritis Rheum. 2010, 62, 3496-3503.

6. Terrier, B.; Bieche, I.; Maisonobe, T.; Laurendeau, I.; Rosenzwajg, M.; Kahn, J.E.; Diemert, M.C.; Musset, L.; Vidaud, M.; Sène, D.; et al. Interleukin-25: A cytokine linking eosinophils and adaptive immunity in Churg-Strauss syndrome. Blood 2010, 116, 4523-4531.

7. Vaglio, A.; Martorana, D.; Maggiore, U.; Grasselli, C.; Zanetti, A.; Pesci, A.; Garini, G.; Manganelli, P.; Bottero, P.; Tumiati, B.; et al. HLADRB4 as a genetic risk factor for Churg-Strauss syndrome. Arthritis Rheum. 2007, 56, 3159-3166.

8. Wieczorek, S.; Hellmich, B.; Gross, W.L.; Epplen, J.T. Associations of Churg-Strauss síndrome with the HLA-DRB1 locus, and relationship to the genetics of antineutrophil cytoplasmic antibody-associated vasculitides: Comment on the article by Vaglio et al. Arthritis Rheum. 2008, 58, 329-330.

9. Buzio, C.; Oliva, E. Diagnosis of Churg-Strauss syndrome: Eotaxin-3 makes it easier. Rheumatology 2011, 50, 1737-1738.

10. Guillevin, L.; Pagnoux, C.; Seror, R.; Mahr, A.; Mouthon, L.; le Toumelin, P. The five-factor score revisited: Assessment of prognoses of systemic necrotizing vasculitides based on the French Vasculitis Study Group (FVSG) cohort. Medicine 2011, 90, 19-27.

11. Zwerina, J.; Bach, C.; Martorana, D.; Jatzwauk, M.; Hegasy, G.; Moosig, F.; Bremer, J.; Wieczorek, S.; Moschen, A.; Tilg, H.; et al. Eotaxin-3 in Churg-Strauss syndrome: A clinical and immunogenetic study. Rheumatology 2011, 50, 1823-1827.

12. Koukoulaki, M.; Smith, K.G.; Jayne, D.R. Rituximab in Churg-Strauss syndrome. Ann. Rheum. Dis. 2006, 65, 557-559.

13. Lanham, J.G.; Elkon, K.B.; Pusey, C.D.; Hughes, G.R. Systemic vasculitis with asthma and eosinophilia: A clinical approach to the Churg-Strauss syndrome. Medicine 1984, 63, 65-81. 
14. Masi, A.T.; Hunder, G.G.; Lie, J.T.; Michel, B.A.; Bloch, D.A.; Arend, W.P.; Calabrese, L.H.; Edworthy, S.M.; Fauci, A.S.; Leavitt, R.Y.; et al. The American College of Rheumatology 1990 criteria for the classification of Churg-Strauss síndrome (allergic granulomatosis and angiitis). Arthritis Rheum. 1990, 33, 1094-1100.

15. Watts, R.A.; Lane, S.; Scott, D.G. What is known about the epidemiology of the vasculitides? Best Pract. Res. Clin. Rheumatol. 2005, 19, 191-207.

16. Herlyn, K.; Hellmich, B.; Gross, W.L.; Reinhold-Keller, E. Stable incidence of systemic vasculitides in schleswig-holstein, Germany. Dtsch. Arztebl. Int. 2008, 105, 355-361.

17. Mahr, A.; Guillevin, L.; Poissonnet, M.; Ayme, S. Prevalences of polyarteritis nodosa, microscopic polyangiitis, Wegener's granulomatosis, and Churg-Strauss syndrome in a French urban multiethnic population in 2000: A capture-recapture estimate. Arthritis Rheum 2004, 51, 92-99.

18. Mohammad, A.J.; Jacobsson, L.T.; Mahr, A.D.; Sturfelt, G.; Segelmark, M. Prevalence of Wegener's granulomatosis, microscopic polyangiitis, polyarteritis nodosa and Churg-Strauss syndrome within a defined population in southern Sweden. Rheumatology 2007, 46, 1329-1337.

19. Moosig, F.; Bremer, J.P.; Hellmich, B.; Holle, J.U.; Holl-Ulrich, K.; Laudien, M.; Matthis, C.; Metzler, C.; Nölle, B.; Richardt, G.; et al. A vasculitis centre based management strategy leads to improved outcome in eosinophilic granulomatosis and polyangiitis (Churg-Strauss, EGPA): Monocentric experiences in 150 patients. Ann. Rheum. Dis. 2013, 72, 1011-1017.

20. Zwerina, J.; Eger, G.; Englbrecht, M.; Manger, B.; Schett, G. Churg-Strauss syndrome in childhood: A systematic literature review and clinical comparison with adult patients. Semin. Arthritis Rheum. 2009, 39, 108-115.

21. Piram, M.; Maldini, C.; Mahr, A. Effect of race/ethnicity on risk, presentation and course of connective tissue diseases and primary systemic vasculitides. Curr. Opin. Rheumatol. 2012, 24, 193-200.

22. Wieczorek, S.; Hellmich, B.; Arning, L.; Moosig, F.; Lamprecht, P.; Gross, W.L.; Epplen, J.T. Functionally relevant variations of the interleukin-10 gene associated with antineutrophil cytoplasmic antibody-negative Churg-Strauss syndrome, but not with Wegener's granulomatosis. Arthritis Rheum. 2008, 58, 1839-1848.

23. Martorana, D.; Maritati, F.; Malerba, G.; Bonatti, F.; Alberici, F.; Oliva, E.; Sebastio, P.; Manenti, L.; Brugnano, R.; Catanoso, M.G.; et al. PTPN22 R620W polymorphism in the ANCA-associated vasculitides. Rheumatology 2012, 51, 805-812.

24. Wieczorek, S.; Hoffjan, S.; Chan, A.; Rey, L.; Harper, L.; Fricke, H.; Holle, J.U.; Gross, W.L.; Epplen, J.T.; Lamprecht, P. Novel association of the CD226 (DNAM-1) Gly307Ser polymorphism in Wegener's granulomatosis and confirmation for multiple sclerosis in German patients. Genes Immun. 2009, 10, 591-595.

25. Wieczorek, S.; Holle, J.U.; Bremer, J.P.; Wibisono, D.; Moosig, F.; Fricke, H.; Assmann, G.; Harper, L.; Arning, L.; Gross, W.L.; et al. Contrasting association of a non-synonymous leptin receptor gene polymorphism with Wegener's granulomatosis and Churg-Strauss syndrome. Rheumatology 2010, 49, 907-914.

26. Hammanci, K.; Anil, H.; Kocak, A.; Dinleyici, E.C. Familial eosinophilic granilomatosis with polyangiitis in a mother and daughter. BMJ Case Rep. 2014, 2014, doi:10.1136/bcr-2014-206934.

27. Lane, S.E.; Watts, R.A.; Bentham, G.; Innes, N.J.; Scott, D.G. Are environmental factors important 
in primary systemic vasculitis? A casecontrol study. Arthritis Rheum. 2003, 48, 814-823.

28. Razek, A.A.; Castillo, M. Imaging appearance of granulomatous lesions of head and neck. Eur $J$ Radiol 2010, 76, 52-60.

29. Hubner, C.; Dietz, A.; Stremmel, W.; Stiehl, A.; Andrassy, H. Macrolide-induced Churg-Strauss syndrome in a patient with atopy. Lancet 1997, 350, doi: 10.1016/S0140-6736(05)63985-2.

30. Lilly, C.M.; Churg, A.; Lazarovich, M.; Pauwels, R.; Hendeles, L.; Rossenwasser, L.J.; Ledford, D.; Wechsler, M.E. Asthma therapies and Churg-Strauss syndrome. J. Allergy Clin. Immunol. 2002, 109, S1-S20.

31. Stirling, R.G.; Chung, K.F. Leukotriene antagonists and Churg-Strauss syndrome: The smoking gun. Thorax 1999, 54, 865-866.

32. Josefson, D. Asthma drug linked with Churg-Strauss syndrome. BMJ 1997, 315, 330, doi:10.1136/ bmj.315.7104.327f.

33. Wechsler, M.E.; Wong, D.A.; Miller, M.K.; Lawrence-Miyasaki, L. Churg-Strauss síndrome in patients treated with omalizumab. Chest 2009, 136, 507-518.

34. Hauser, T.; Mahr, A.; Metzler, C.; Coste, J.; Sommerstein, R.; Gross, W.L.; Guillevin, L.; Hellmich, B. The leucotriene receptor antagonist montelukast and the risk of Churg-Strauss syndrome: A casecrossover study. Thorax 2008, 63, 677-682.

35. Bibby, S.; Healy, B.; Steele, R.; Kumareswaran, K.; Nelson, H.; Beasley, R. Association between leukotriene receptor antagonist therapy and Churg-Strauss syndrome: An analysis of the FDA AERS database. Thorax 2010, 65, 132-138.

36. Iglesis, E.; Camacho Lovillo, M.; Delgado Pellecín, I.; Lirola Cruz, M.J.; Falcon Neyra, M.D.; Salazar Quero, J.C.; Bernabeu-Wittel, J.; González Valencia, J.P.; Neth, O. Successful management of Churg-Strauss syndrome ursing omalizumab as adjuvant immunomodulatory therapy: First documented peadiatric case. Pediatr. Pulmonol. 2014, 49, E78-E81.

37. Graziani, A.; Quercia, O.; Girelli, F.; Martelli, A.; Mirici Cappa, F.; Stefanini, G.F. Omalizumab treatment in patient with severe asthma and eosinophilic granulomatosis with polyangiitis. A case report. Eur. Ann. Allergy Clin. Immunol. 2014, 46, 226-228.

38. Vaglio, A.; Casazza, I.; Grasselli, C.; Corradi, D.; Sinico, R.A.; Buzio, C. Churg-Strauss syndrome. Kidney Int. 2009, 76, 1006-1011.

39. Noth, I.; Strek, M.E.; Leff, A.R. Churg-Strauss syndrome. Lancet 2003, 361, 587-594.

40. Lie, J.T. Limited forms of Churg-Strauss syndrome. Pathol. Annu. 1993, 28, 199-220.

41. Bacciu, A.; Bacciu, S.; Mercante, G.; Ingegnoli, F.; Grasselli, C.; Vaglio, A.; Pasanisi, E.; Vincenti, V.; Garini, G.; Ronda, N.; et al. Ear, nose and throat manifestations of Churg-Strauss syndrome. Acta Otolaryngol. 2006, 126, 503-509.

42. Bacciu, A.; Buzio, C.; Giordano, D.; Pasanisi, E.; Vincenti, V.; Mercante, G.; Grasselli, C.; Bacciu, S. Nasal polyposis in Churg-Strauss syndrome. Laryngoscope 2008, 118, 325-329.

43. Alobid, I.; Guilemany, J.M.; Mullol, J. Nasal manifestations of systemic illnesses. Curr. Allergy Asthma Rep. 2004, 4, 208-216.

44. Alobid, I.; Mullol, J.; Cid, M.C. Rinitis of granulomatous and vasculitic diseases. Clin. Allergy Immunol. 2007, 19, 221-239.

45. Bottero, P.; Bonini, M.; Vecchio, F.; Grittini, A.; Patruno, G.M.; Colombo, B.; Sinico, R.A. The common allergens in the Churg-Strauss syndrome. Allergy 2007, 62, 1288-1294. 
46. Keogh, K.A.; Specks, U. Churg-Strauss syndrome. Semin. Respir. Crit. Care Med. 2006, 27, $148-157$.

47. Kim, Y.K.; Lee, K.S.; Chung, M.P.; Han, J.; Chong, S.; Chung, M.J.; Chin, A.Y.; Kim, H.Y. Pulmonary involvement in Churg-Strauss syndrome: An analysis of CT, clinical, and pathologic findings. Eur. Radiol. 2007, 17, 3157-3165.

48. Guillevin, L.; Cohen, P.; Gayraud, M.; Lhote, F.; Jarrousse, B.; Casassus, P. Churg-Strauss syndrome. Clinical study and long-term followup of 96 patients. Medicine 1999, 78, 26-37.

49. Sinico, R.A.; di Toma, L.; Maggiore, U.; Bottero, P.; Radice, A.; Tosoni, C.; Grasselli, C.; Pavone, L.; Gregorini, G.; Monti, S.; et al. Prevalence and clinical significance of antineutrophil cytoplasmic antibodies in Churg-Strauss syndrome. Arthritis Rheum. 2005, 52, 2926-2935.

50. Guillevin, L.; Lhote, F.; Gayraud, M.; Cohen, P.; Jarrousse, B.; Lortholary, O.; Thibult, N.; Casassus, P. Prognostic factors in polyarteritis nodosa and Churg-Strauss syndrome. A prospective study in 342 patients. Medicine 1996, 75, 17-28.

51. Neumann, T.; Manger, B.; Schmid, M.; Kroegel, C.; Hansch, A.; Kaiser, W.A.; Reinhardt, D.; Wolf, G.; Hein, G.; Mall, G.; et al. Cardiac involvement in Churg-Strauss syndrome: Impact of endomyocarditis. Medicine 2009, 88, 236-243.

52. Dennert, R.M.; van Paassen, P.; Schalla, S.; Kuznetsova, T.; Alzand, B.S.; Staessen, J.A.; Velthuis, S.; Crijns, H.J.; Tervaert, J.W.C.; Heymans, S. Cardiac involvement in Churg-Strauss syndrome. Arthritis Rheum. 2010, 62, 627-634.

53. Allenbach, Y.; Seror, R.; Pagnoux, C.; Teixeira, L.; Guilpain, P.; Guillevin, L. High frequency of venous thromboembolic events in Churg-Strauss syndrome, Wegener's granulomatosis and microscopic polyangiitis but not polyarteritis nodosa: A systematic retrospective study on 1130 patients. Ann. Rheum. Dis. 2009, 68, 564-567.

54. Vaglio, A.; Corradi, D.; Ronda, N.; Garini, G.; Buzio, C. Large bowel obstruction heralding Churg-Strauss syndrome. Am. J. Gastroenterol. 2004, 99, 562-563.

55. Sable-Fourtassou, R.; Cohen, P.; Mahr, A.; Pagnoux, C.; Mouthon, L.; Jayne, D.; Blockmans, D.; Cordier, J.F.; Delaval, P.; Puechal, X.; et al. Antineutrophil cytoplasmic antibodies and the Churg-Strauss syndrome. Ann. Intern. Med. 2005, 143, 632-638.

56. Sironen, R.K.; Seppa, A.; Kosma, V.M.; Kuopio, T. Churg-Strauss syndrome manifested by appendicitis, cholecystitis and superficial micronodular liver lesions-an unusual clinicopathological presentation. J. Clin. Pathol. 2010, 63, 848-850.

57. Keogh, K.A.; Specks, U. Churg-Strauss syndrome: Clinical presentation, antineutrophil cytoplasmic antibodies, and leukotriene receptor antagonists. Am. J. Med. 2003, 115, 284-290.

58. Cattaneo, L.; Chierici, E.; Pavone, L.; Grasselli, C.; Manganelli, P.; Buzio, C.; Pavesi, G. Peripheral neuropathy in Wegener's granulomatosis, Churg-Strauss syndrome and microscopic polyangiitis. J. Neurol. Neurosurg. Psychiatry 2007, 78, 1119-1123.

59. Healy, B.; Bibby, S.; Steele, R.; Weatherall, M.; Nelson, H.; Beasley, R. Antineutrophil cytoplasmic autoantibodies and myeloperoxidase autoantibodies in clinical expression of Churg-Strauss syndrome. J. Allergy Clin. Immunol. 2013, 131, doi:10.1016/j.jaci.2012.05.058.

60. Gendelman, S.; Zeft, A.; Spalding, S.J. Childhood-onset eosinophilic granulomatosis with polyangiitis (formerly Churg-Strauss syndrome): A contemporary single-center cohort. J. Rheumatol. 2013, 40, 929-935. 
61. Pagnoux, C.; Guilpain, P.; Guillevin, L. Churg-Strauss syndrome. Curr. Opin. Rheumatol. 2007, $19,25-32$.

62. Vaglio, A.; Strehl, J.D.; Manger, B.; Maritati, F.; Alberici, F.; Beyer, C.; Rech, J.; Sinico, R.A.; Bonatti, F.; Battistelli, L.; et al. IgG4 immune response in Churg-Strauss syndrome. Ann. Rheum. Dis. 2012, 71, 390-393.

63. Zwerina, J.; Axmann, R.; Manger, B.; Schett, G. The emergence of antineutrophil cytoplasmic antibodies may precede the clinical onset of Churg-Strauss syndrome. Arthritis Rheum. 2009, 60, $626-627$.

64. Herrmann, K.; Gross, W.L.; Moosig, F. Extended follow-up after stopping mepolizumab in relapsing/refractory Churg-Strauss Syndrome. Clin. Exp. Rheumatol. 2012, 30, S62-S65.

65. Grayson, P.C.; Monach, P.A.; Pagnoux, C.; Cuthbertson, D.; Carette, S.; Hoffman, G.S.; Khalidi, N.A.; Koening, C.L.; Langford, C.A.; Maksimowicz-McKinnon, K.; et al. Value of commonly measured laboratory tests as biomarkers of disease activity and predictors of relapse in eosinophilic granulomatosis with polyangiitis. Rheumatology. 2015, 54, 1351-1359.

66. Jeong, Y.J.; Kim, K.I.; Seo, I.J.; Lee, C.H.; Lee, K.N.; Kim, K.N.; Kim, J.S.; Kwon, W.J. Eosinophilic lung disease: A clinical, radiological and pathological view. Radiographic 2007, 27, 617-637.

67. Szczeklik, W.; Sokolowska, B.; Mastalerz, L.; Grzanka, P.; Górka, J.; Pacułt, K.; Miszalski-Jamka, T.; Soja, J.; Musiał, J. Pulmonary findings in Churg-Strauss syndrome in chest radiography and high resolution computed tomography at the time of initial diagnosis. Clin. Rheumatol. 2010, 29, $1127-1134$.

68. Furuiye, M.; Yoshimura, N.; Kobayashi, A.; Tamaoka, M.; Miyazaki, Y.; Ohtani, Y.; Miyake, S.; Inase, N.; Yoshizawa, Y. Churg-Strauss versus chronic eosinophilic pneumonia in high resolution computed tomography findings. J. Comput. Assist. Tomogr. 2010, 34, 19-22.

69. Lund, V.J.; Mackay, I.S. Stating in rhinosinusitis. Rhinology 1993, 31, 183-184.

70. Metson, R.; Gliklich, R.E.; Stankiewicz, J.A.; Kennedy, D.W.; Duncavange, J.A.; Hofman, S.R.; Ohnishi, T.; Terrell, J.E.; White, P.S. Comparison of sinus computer tomography staging system. Otolaryngol Head Neck Surg. 1997, 117, 372-379.

71. Fokkens, W.J.; Lund, V.J.; Mullol, J.; Bachert, C.; Alobid, I.; Baroody, F.; Cohen, N.; Cervin, A.; Douglas, R.; Gevaert, P.; et al. EPOS 2012: European position paper on rhinosinusitis and nasal polyps 2012. A summary for otorhinolaryngologists. Rhinology 2012, 50, 1-12.

72. Szczeklik, W.; Sokolowska, B.M.; Zuk, J.; Mastalerz, L.; Szczeklik, A.; Musiał, J. The course of asthma in Churg Strauss syndrome. J. Asthma 2011, 48, 183-187.

73. Lotvall, J.; Akdis, C.A.; Bacharier, L.B.; Bjermer, L.; Casale, T.B.; Custovic, A.; Lemanske, R.F.; Wardlaw, A.J.; Wenzel, S.E.; Greenberger, P.A. Endotypes asthma: A new approach to classification of disease entities asthma syndrome. J. Allergy Clin. Inmunol. 2011, 127, 355-360.

74. Amelink, M.; de Groot, J.C.; de Nijs, S.B.; Lutter, R.; Zwinderman, A.H.; Sterk, P.J.; ten Brinke, A.; Bel, E.H. Severe adult-onset asthma: A distinct phenotype. J. Allergy Clin. Immunol. 2013, 132, 336-341.

75. Szczeklik, W.; Grzanka, P.; Mastalerz, L.; Sokołowska, B.; Musial, J. Lung involvement in Churg-Strauss. syndrome as related to the activity of the disease. Allergy 2010, 65,1484-1485.

76. Szczeklik, W.; Jakiela, B.; Adamek, D.; Musial, J. cutting-edge issues in the Churg Strauss 
syndrome. Clin. Rev. Allergy Immunol. 2013, 44, 39-50.

77. Groh, M.; Pagnoux, C.; Baldini, C.; Bel, E.; Bottero, P.; Cottin, V.; Dalhoff, K.; Dunogué, B.; Gross, W.; Holle, J.; et al. Eosinophilic granulomatosis with polyangiitis (Churg-Strauss) (EGPA) Consensus Task Force recommendations for evaluation and management. Eur. J. Intern. Med. 2015, 26, 545-553.

78. Simon, H.U.; Rothenberg, M.E.; Bochner, B.S.; Weller, P.F.; Wardlaw, A.J.; Wechsler, M.E.; Rosenwasser, L.J.; Roufosse, F.; Gleich, G.J.; Klion, A.D. Refining the definition of hypereosinophilic syndrome. J. Allergy Clin. Immunol. 2010, 126, 45-49.

79. Gotlib, J. World Health Organization-defined eosinophilic disorders: 2012 update on diagnosis, risk stratification, and management. Am. J. Hematol. 2012, 87, 903-914.

80. Khoury, P.; Zagallo, P.; Talar-Williams, C.; Santos, C.S.; Dinerman, E.; Holland, N.C.; Klion, A.D. Serum biomarkers are similar in Churg-Strauss syndrome and hypereosinophilic syndrome. Allergy 2012, 67, 1149-1156.

81. Corradi, D.; Vaglio, A.; Maestri, R.; Legname, V.; Leonardi, G.; Bartoloni, G.; Buzio, C. Eosinophilic myocarditis in a patient with idiopathic hypereosinophilic syndrome: Insights into mechanisms of myocardial cell death. Hum. Pathol. 2004, 35, 1160-1163.

82. Polzer, K.; Karonitsch, T.; Neumann, T.; Eger, G.; Haberler, C.; Soleiman, A.; Hellmich, B.; Csernok, E.; Distler, J.; Manger, B.; et al. Eotaxin-3 is involved in Churg-Strauss síndrome a serum marker closely correlating with disease activity. Rheumatology 2008, 47, 804-808.

83. Sinico, R.A.; Bottero, P. Churg-Strauss angiitis. Best Pract. Res. Clin. Rheumatol. 2009, 23, $355-366$.

84. Wechsler, M.E. Pulmonary eosinophilic syndromes. Immunol. Allergy Clin. N. Am 2007, 27, 477-492.

85. Stone, J.H.; Zen, Y.; Deshpande, V. IgG4-related disease. N. Engl. J. Med. 2012, 366, 539-551.

86. Vaglio, A.; Zwerina, J. IgG4-related disease. N. Engl. J. Med. 2012, 366, 1646-1647.

87. Fujita, A.; Sakai, O.; Chapman, M.N.; Sugimoto, H. IgG4-related disease of the head and neck: CT and MR imaging manifestations. RadioGraphics 2012, 32, 1945-1958.

88. Cohen, P.; Pagnoux, C.; Mahr, A.; Arene, J.P.; Mouthon, L.; le Guern, V.; André, M.H.; Gayraud, M.; Jayne, D.; Blöckmans, D.; et al. Churg-Strauss syndrome with poor-prognosis factors: A prospective multicenter trial comparing glucocorticoids and six or twelve cyclophosphamide pulses in forty-eight patients. Arthritis Rheum. 2007, 57, 686-693.

89. Ribi, C.; Cohen, P.; Pagnoux, C.; Mahr, A.; Arene, J.P.; Lauque, D.; Puéchal, X.; Letellier, P.; Delaval, P.; Cordier, J.F.; et al. Treatment of Churg-Strauss syndrome without poor-prognosis factors: A multicenter, prospective, randomized, open-label study of seventy-two patients. Arthritis Rheum. 2008, 58, 586-594.

90. Metzler, C.; Hellmich, B.; Gause, A.; Gross, W.L.; de Groot, K. Churg-Strauss syndrome-successful induction of remission with methotrexate and unexpected high cardiac and pulmonary relapse ratio during maintenance treatment. Clin. Exp. Rheumatol. 2004, 22 (Suppl. S36), S52-S61.

91. Danieli, M.G.; Cappelli, M.; Malcangi, G.; Logullo, F.; Salvi, A.; Danieli, G. Long term effectiveness of intravenous immunoglobulin in Churg-Strauss syndrome. Ann. Rheum. Dis. 2004, 63, 1649-1654.

92. Tatsis, E.; Schnabel, A.; Gross, W.L. Interferonalpha treatment of four patients with the Churg-Strauss 
syndrome. Ann. Intern. Med. 1998, 129, 370-374.

93. Metzler, C.; Schnabel, A.; Gross, W.L.; Hellmich, B. A phase II study of interferon-alpha for the treatment of refractory Churg-Strauss syndrome. Clin. Exp. Rheumatol. 2008, 26 (Suppl. S49), S35-S40.

94. Metzler, C.; Csernok, E.; Gross, W.L.; Hellmich, B. Interferon-alpha for maintenance of remission in Churg-Strauss syndrome: A long-term observational study. Clin. Exp. Rheumatol. 2010, 28 (Suppl. S57), 24-30.

95. Corren, J. Anti-interleukin-5 antibody therapy in asthma and allergies. Curr. Opin. Allergy Clin. Immunol. 2011, 11, 565-570.

96. Kahn, J.E.; Grandpeix-Guyodo, C.; Marroun, I.; Catherinot, E.; Mellot, F.; Roufosse, F.; Blétry, O. Sustained response to mepolizumab in refractory Churg-Strauss syndrome. J. Allergy Clin. Immunol. 2010, 125, 267-270.

97. Kim, S.; Marigowda, G.; Oren, E.; Israel, E.; Wechsler, M.E. Mepolizumab as a steroidsparing treatment option in patients with Churg-Strauss syndrome. J. Allergy Clin. Immunol. 2010, 125, 1336-1343.

98. Moosig, F.; Gross, W.L.; Herrmann, K.; Bremer, J.P.; Hellmich, B. Targeting interleukin-5 in refractory and relapsing Churg-Strauss syndrome. Ann. Intern. Med. 2011, 155, 341-343.

99. Cartin-Ceba, R.; Keogh, K.A.; Specks, U.; Sethi, S.; Fervenza, F.C. Rituximab for the treatment of Churg-Strauss syndrome with renal involvement. Nephrol. Dial. Transplant. 2011, 26, 2865-2871.

100. Jones, R.B.; Ferraro, A.J.; Chaudhry, A.N.; Brogan, P.; Salama, A.D.; Smith, K.G.; Savage, C.O.; Jayne, D.R. A multicenter survey of rituximab therapy for refractory antineutrophil cytoplasmic antibody-associated vasculitis. Arthritis Rheum. 2009, 60, 2156-2168.

101. Pepper, R.J.; Fabre, M.A.; Pavesio, C.; Gaskin, G.; Jones, R.B.; Jayne, D.; Pusey, C.D.; Salama, A.D. Rituximab is effective in the treatment of refractory Churg-Strauss syndrome and is associated with diminished T-cell interleukin-5 production. Rheumatology 2008, 47, 1104-1105.

102. Alobid, I.; Mullol, J. Role of medical therapy in the management of nasal polyps. Curr. Allergy Asthma Rep. 2012, 12, 144-153.

(C) 2015 by the authors; licensee MDPI, Basel, Switzerland. This article is an open access article distributed under the terms and conditions of the Creative Commons Attribution license (http://creativecommons.org/licenses/by/4.0/). 